\title{
Notas sobre uma especificidade do mate paranaense no século XIX
}

\author{
Carlos Alberto Medeiros Lima ${ }^{1}$
}

Resumo: As presentes notas tratam de uma peculiaridade da coleta de erva mate praticada no Paraná durante a segunda metade do século XIX. Através de inventários post mortem abertos em São José dos Pinhais e Campo Largo, enfatiza-se a propriedade privada de ervais nativos, criando-se uma situação diferente da observada em outras áreas do Sul brasileiro durante o mesmo intervalo.

Palavras chave: erva mate - Paraná no século XIX - sociedade e economia

\section{Notes on the peculiarity of nineteenth-century yerba maté collection in Paraná, Brazil}

\begin{abstract}
These notes deal with the peculiarity of the yerba maté collection practiced at Paraná during the second half of the nineteenth century. Using probate inventories proceeded at São José dos Pinhais and Campo Largo, the article stresses the fact that yerbales frequently belonged to individual proprietors, which was different from the extraction practiced in other parts of Southern Brazil during the same period.
\end{abstract}

Keywords: yerba maté - Paraná during the nineteenth century - economy and society

- Enviado em 13/05/2017

- Aprovado em 28/06/2017

${ }^{1}$ Professor de História da UFPR / CNPq. E-mail: carlima3@gmail.com 
No sul da província de São Paulo, que atualmente corresponde ao Paraná, a primeira metade do séuclo XIX já foi marcada pela ascensão da coleta, do fraco beneficiamento e da exportação de erva mate. Isso produziu uma elite peculiar, pois, como se verá, a atividade produzia muitos rendimentos para o capital mercantil, mas poucos traços na paisagem agrária.

Extensa historiografia que tem em vista processos gaúchos ou catarinenses, assim como os paranaenses do século XX (WACHOWICZ, 1977; ZARTH, 1997, p. 117; FONTELLA, 2013, p. 99-100; MYSKIW, 2009, p. 153; CAMPOS, 1991, p. 57-61, nesse caso discutindo bibliografia sobre os faxinais paranaenses), deu muita ênfase à coleta realizada em terras devolutas, em áreas de fronteira muito distantes dos núcleos organizados. Mas o peculiar das áreas ervateiras paranaenses, especialmente no século XIX, estava no fato de que os ervais começaram a ser explorados de modo mais extenso no intervalo muito peculiar da vida brasileira estendido entre 1822 e 1850 (LIMA, 2011; PEREIRA, 1996; WESTPHALEN, 1998, p. 165, 519), momento durante o qual não existia regulação para a apropriação de baldios, em vista da supressão das sesmarias em 1822 e do dilatado período de formulação e negociação da Lei de Terras, que só viria a ser promulgada em 1850 .

Isso significa que a atividade aludida, filha da dispersão e da precariedade na fase da coleta, pôde ser formada em concomitância com a espécie de epidemia de formação de posses grandes e pequenas que teve lugar em função da ausência de regulação da apropriação de baldios. Os dois processos - estabelecimento da coleta em mais larga escala e formação de posses - tinham exatamente isso em comum, ou seja, o fato de se terem organizado ao longo de um eixo velozmente dispersivo e extremamente precário.

Resulta, é preciso insistir, um quadro no qual muito do mate coletado no século XIX saía de propriedades estabelecidas - se essa designação couber à farra da apropriação de baldios ocorrida entre 1822 e 1850, que também esteve implicada na formação de muitas das regiões produtoras do principal produto da agroexportação brasileira do século XIX, o café (MOTTA, 1998; MUNIZ, 2001, p. 389-400; MATTOS, 1995, parte I). Assim, os ervais podem ser localizados com facilidade no interior das propriedades transmitidas entre gerações através dos inventários post mortem processados durante a segunda metade do século XIX. Como se sabe, a Lei de Terras regularizou através do Registro Paroquial de Terras as posses obtidas no período da farra, tendo inclusive rearranjado a distribuição, no sentido de forçar algumas das pequenas posses a desaparecerem 
em favor de grandes tratos então também regulados. Robert Smith data a formação do latifúndio no Brasil mais do intervalo 1822-1850 que da promulgação da Lei de Terras, do segundo daqueles anos (SMITH, 1990, p. 304). No entanto, e também como novidade, o Registro Paroquial de Terras significou a concessão de títulos de propriedade a posseiros que de outra forma não os teriam, enchendo foros locais de inventários post mortem que, pelo menos durante o terceiro e parte do último quartos do século XIX, foram abertos inclusive para proprietários de ínfimas posses, às vezes mesmo de posses inviáveis.

Esses inventários permanecem nas varas cíveis dos diversos foros locais no Paraná, e as andanças para buscá-los permitem mapear as áreas onde os ervais apropriados podiam ser encontrados. Foram consultados 540 desses processos. Em Campo Largo (1872-1885) e São José dos Pinhais (1852-1886), quatro quintos ou um pouco mais dos patrimônios inventariados manifestavam algum tipo de terreno com indício de possuir ervais (Inventários post mortem, 1852-1886, Cartório da $2^{\text {a }}$ Vara Cível de São José dos Pinhais; Inventários post mortem, 1872-1885, Vara Cível de Campo Largo). Quando se passa aos apenas vinte e cinco inventários localizados no que toca a Palmeira no intervalo 1874-1888, a proporção daqueles que continham ervais desce para cerca de um terço (Inventários post mortem, 1874-1888, Fórum de Palmeira, Vara Cível de Palmeira). Por fim, inventários de escravistas em Guarapuava consultados para o intervalo 18501880 por Fernando Franco Netto chamam a atenção pela completa ausência de referências ao mate (FRANCO NETTO, 2007, p. 272). Havia um problema ambiental envolvido, certamente. Restam poucas dúvidas de que se estava, no tocante à propriedade de ervais, diante de um fenômeno próprio do planalto curitibano.

Os inventários permitem uma aproximação aos tipos de bem agrário aos quais os de São José dos Pinhais e Campo Largo direcionavam seus investimentos. Dada a singeleza das atividades econômicas locais, essa tarefa pode ser simplificada pensando-se em três tipos básicos de direcionamento.

Primeiramente, a agricultura do milho e do feijão. Ela será verificada especialmente através da classificação dos terrenos e benfeitorias pelos avaliadores em alguns tipos: capoeiras, mato, caívas, mato virgem, terras de planta, paióis, monjolos, terrenos de caíva, capoeira de planta, capoeiras lavradias, terrenos de capoeira, matos lavradios, terrenos de planta, partes de mato, partes de terrenos ou terras lavradias. É impossível separar benfeitorias ou roças dos terrenos, pois a fonte não o fez. É igualmente inviável separar produtos já colhidos dos terrenos e 
benfeitorias, chegando a ser espantosa a raridade dos casos em que algum produto (alqueires ou mãos de milho) aparecia nas avaliações (totalmente inconsistente com as referências a capoeiras ou terras de planta nas mesmas avaliações).

Em segundo lugar, a pecuária bovina e cavalar aparecia através de alguns tipos de terreno e/ou benfeitoria (normalmente associados nas avaliações): campo, mangueira, potreiro, terreno de pastagem, faxinais, currais, campinas, matos de pastagem, caívas de pastagem ou invernadas. Alguns tipos de terreno/benfeitoria tiveram que ser entendidos como referindo tanto agricultura de alimentos quanto criação de animais. Era o caso das (ínfimas, é bom que se diga) "esterqueiras". Mais singular, no interior do procedimento, foi a necessidade de associar à pecuária espólios que não pareciam conter terrenos ou benfeitorias ligadas à criação. Em alguns desses casos, apesar da falta de referência a terrenos apropriados, havia a propriedade de animais possivelmente criados $^{2}$. Foi necessário fazer a posse de animais interferir na classificação dos espólios pelo fato de que o produto da agricultura não aparecia separado (a erva-mate já colhida também raramente o fazia), sendo certamente avaliado juntamente com a terra e as benfeitorias. Assim, a posse de animais provavelmente criados localmente teve que ser tratada do mesmo jeito, embora os animais fossem avaliados separadamente da terra e das benfeitorias.

Por fim, classificaram-se espólios como tendo alguma participação na coleta de erva-mate quando aparecessem classificações de terrenos como as seguintes: erval, "com alguma ervamate", "com pouca erva-mate", terrenos de erval, gramados de erval, capoeiras de erval, caívas de erval, ou matos de erval. Não se deve perder de vista tratar-se aqui apenas da coleta de ervamate.

É claro que o fato de se ter terrenos apropriados à agricultura ou à pecuária não significava necessariamente que qualquer uma delas fosse praticada. Da mesma forma, o fato de não se ter terrenos avaliados como apropriados a alguma das atividades não significava que ela não fosse executada. Trata-se, como se vê, de muita evidência indireta, além do mais vazada em linguagem carregada de ambiguidades. Boa parte dos bens avaliados apresentava mais de uma inserção;

\footnotetext{
2 Por posse de animais se faz referência a qualquer tipo de animal, excetuando-se os muares, pois estes não eram criados nas áreas estudadas. A questão, de fato, está a merecer reexame. Estudos sobre áreas novas e antigas no Paraná durante o século XIX sugerem que as mulas ainda vinham do Sul, em meio a uma decadência geral do negócio, notadamente na segunda metade do século. Ver MACHADO, 2002, p. 61-92; KLEIN, 1989; MACHADO, WESTPHALEN, BALHANA, 1968; MENDES, 1989; PETRONE, 1976. Estudos sobre listas nominativas das áreas de criação do Paraná mostram que, mesmo após a independência, e nos casos em que as referidas listas mostravam os números por domicílio de animais "marcados" ao longo do ano, predominavam bovinos e cavalares, com muito poucos animais "marcados" designados como "muares". Cf., por exemplo, LIMA, 2004.
} 
muitos, ao final da leitura das descrições, só puderam ser entendidos como possibilitando as três atividades conjuntamente.

O resultado era que quase todo mundo fazia quase tudo (agricultura, criação de gado e coleta de erva-mate) ao mesmo tempo. Ainda assim, há determinadas tendências quanto à distribuição dos espólios por tais atividades que podem ser monitoradas do jeito que se propõe aqui, conforme será visto, sendo de resto de lembrar-se que a combinação de atividades diferentes obedecia a injunções provenientes do mercado, sempre instável no tocante a um produto em particular, e assim induzindo as pessoas a acumular atividades diferentes. Além disso, a posse de boa parte dos ativos podia dar lugar a duas relações muito diferentes com os mesmos, e é impossível somente com os inventários decidir entre elas: podia-se usá-los como gestor, ou então podia haver um posicionamento de rentista em relação a eles, sobretudo em se tratando de terra. Isso sem falar que detectar que alguém plantava alimentos não significa de modo algum conseguir saber as dimensões disso. Nos casos de combinação de ocupações, é impossível saber qual era o tamanho relativo de cada uma. Nem mesmo o problema de saber se a produção agrária se destinava ao mercado ou se era para o consumo da própria unidade pode ser resolvido. Mas, apesar de todas essas ressalvas, é possível ler movimentos consistentes.

Observando a tabela 1, vê-se terem sido muito intensas e estáveis as ligações entre posse de escravos e agricultura, como se vê na tabela a seguir. Era-o igualmente a articulação entre posse de escravos e pecuária. Era muito menos frequente e bem menos estável a associação entre a posse de escravos e a de ervais. Realmente, a posse de ervais não estava particularmente associada ao tamanho das escravarias. Nos dois lugares, nota-se mesmo uma tendência um pouco menos pronunciada a que os maiores senhores de escravos possuíssem aquele tipo de terreno.

Tudo poderia ter se tratado do fato de que as pessoas não escolhiam ter ou não mate nos terrenos que já possuíssem, o que explicaria o fato de terrenos adequados à coleta de erva mate terem sido mais raros. Mas se introduzirmos uma variável que indique a riqueza desses inventariados (usamos a posse de escravos) veremos que não se tratava de acaso: pessoas sem escravos tinham mais chances que escravistas de possuírem ervais. 
Tabela 1

Presença nos inventários de bens agrários adequados a diversos tipos de utilização, de acordo com a posse de escravos (São José dos Pinhais, 1852-1886 e Campo Largo, 1872-1885)

Em percentagens do total de inventários em cada caso

\begin{tabular}{lcccccc}
\hline & \multicolumn{3}{c}{ S. J. dos Pinhais, 1852-1886 - faixas } & \multicolumn{3}{c}{ C. Largo, 1872-1885 - faixas de } \\
posse
\end{tabular}

Em números absolutos de inventários

\begin{tabular}{lcccccc}
\hline & \multicolumn{3}{c}{ S. J. dos Pinhais, 1852-1886 - faixas } & \multicolumn{3}{c}{ C. Largo, 1872-1885 - faixas de } \\
de posse & \multicolumn{3}{c}{ posse } \\
\hline \multirow{2}{*}{ Usos } & $\begin{array}{c}\text { Sem } \\
\text { escravos }\end{array}$ & $\begin{array}{c}1 \text { a } 4 \\
\text { escravos }\end{array}$ & $\begin{array}{c}5 \text { ou }+ \\
\text { escravos }\end{array}$ & $\begin{array}{c}\text { Sem } \\
\text { escravos }\end{array}$ & $\begin{array}{c}1 \text { a } 4 \\
\text { escravos }\end{array}$ & $\begin{array}{c}5 \text { ou + } \\
\text { escravos }\end{array}$ \\
\hline Agricultura de alimentos & 212 & 66 & 19 & 85 & 44 & 10 \\
Criação de gado & 200 & 63 & 19 & 81 & 46 & 10 \\
Coleta de erva mate & 155 & 44 & 11 & 64 & 35 & 5 \\
\hline \multirow{2}{*}{ Total de inventários } & 265 & 70 & 20 & 98 & 51 & 11 \\
\hline
\end{tabular}

Fontes: Inventários post mortem, 1852-1886, Cartório da $2^{a}$ Vara Cível de São José dos Pinhais; Inventários post mortem, 1872-1885, Vara Cível de Campo Largo. 
Para os inventariados sem escravos era um pouco menor o comprometimento com a agricultura de alimentos, ou então a terra usada por esses proprietários não era das mais adequadas. Inversamente, podia ser um pouco mais elevada a ligação com a posse de ervais. A relativa frouxidão da ligação entre a posse de ervais e a escravidão indica que possuir ervais não era coisa de ricos.

Especialmente no tocante a Campo Largo fica-se com a impressão de que, crescendo a ligação de cada proprietário com a escravidão, a relação com a posse de ervais ou era indiferente, ou se reduzia francamente. Por outro lado, quanto maiores as fortunas, maior a tendência à presença de bens que tornavam possível tanto a pecuária quanto a agricultura. A possibilidade de praticar a agricultura e a pecuária concentrava substancialmente mais os esforços daqueles que para padrões locais eram muito ricos.

A propensão a possuir ervais pode ser diretamente relacionada ao tamanho dos patrimônios inventariados. Para tal, foi preciso deflacionar os valores dos montes brutos, o que se fez utilizando o índice de preços formulado há anos por Eulalia Lobo (LOBO, 1971), o qual permitiu converter os valores em milhares de réis constantes conforme o poder de compra de 1872 (tabela 2).

Ao relacionar posse de escravos e fortuna inventariada, percebe-se uma parábola. A propensão a ter ervais aumentava com o tamanho das fortunas, mas apenas para passar a movimentar-se inversamente às dimensões dos patrimônios quando se atingia os segmentos superiores da sociedade. Em São José, a faixa mais propensa a possuir ou conservar a propriedade de ervais congregava aqueles cujas fortunas estavam entre os 5 e os quinze contos de réis constantes. Em Campo Largo os possuidores de ervais estavam ainda mais distantes do topo da sociedade, pois ervais apareciam com maior frequência entre os bens dos que faleceram com fortunas de entre dois e cinco contos. Possuir ervais não era algo que se acoplasse à condição dos mais ricos nos locais estudados. 
Tabela 2

Inventariados por faixa de fortuna - Presença de bens agrários adequados a diversos tipos de utilização (São José dos Pinhais, 1852-1886 e Campo Largo, 1872-1885)

Em percentagens do total de inventários em cada caso

\begin{tabular}{|c|c|c|c|c|c|c|c|c|}
\hline \multirow[b]{2}{*}{ Usos } & \multicolumn{4}{|c|}{$\begin{array}{l}\text { S. J. dos Pinhais, } 1852-1886- \\
\text { faixas de fortuna }\end{array}$} & \multicolumn{4}{|c|}{$\begin{array}{l}\text { C. Largo, } 1872-1885 \text { - faixas de } \\
\text { fortuna }\end{array}$} \\
\hline & $\begin{array}{c}<2 \\
\text { cont } \\
\text { os }\end{array}$ & $\begin{array}{c}2-4,9 \\
\text { cont } \\
\text { os }\end{array}$ & $\begin{array}{c}5- \\
14,9 \\
\text { cont } \\
\text { os }\end{array}$ & $\begin{array}{l}>=15 \\
\text { contos }\end{array}$ & $\begin{array}{c}<2 \\
\text { conto } \\
\mathrm{s}\end{array}$ & $\begin{array}{c}2-4,9 \\
\text { cont } \\
\text { os }\end{array}$ & $\begin{array}{c}5- \\
14,9 \\
\text { cont } \\
\text { os }\end{array}$ & $\begin{array}{l}>=15 \\
\text { contos }\end{array}$ \\
\hline $\begin{array}{l}\text { Agric. de alimentos } \\
\text { Criação de gado } \\
\text { Erva mate }\end{array}$ & $\begin{array}{l}91,1 \\
83,3 \\
64,6\end{array}$ & $\begin{array}{l}94,5 \\
94,5 \\
63,0\end{array}$ & $\begin{array}{l}97,6 \\
97,6 \\
78,6\end{array}$ & $\begin{array}{l}92,3 \\
92,3 \\
53,8\end{array}$ & $\begin{array}{l}83,6 \\
76,1 \\
\mathbf{5 5 , 2}\end{array}$ & $\begin{array}{l}89,1 \\
93,5 \\
78,3\end{array}$ & $\begin{array}{l}92,9 \\
92,9 \\
69,0\end{array}$ & $\begin{array}{l}100,0 \\
100,0 \\
66,7\end{array}$ \\
\hline $\begin{array}{l}\text { Total de } \\
\text { inventários }\end{array}$ & 100 & 100 & 100 & 100 & 100 & 100 & 100 & 100 \\
\hline Em números absolu & $\frac{\text { os de in }}{\text { S. J. }}$ & $\begin{array}{l}\text { entários } \\
\text { os Pinhai } \\
\text { faixas de }\end{array}$ & $\begin{array}{l}1852-1 \\
\text { fortuna }\end{array}$ & $86-$ & C. La & $\begin{array}{r}1872-1 \\
\text { fort }\end{array}$ & $\begin{array}{l}385-\text { fai } \\
\text { na }\end{array}$ & ras de \\
\hline Usos & $\begin{array}{c}<2 \\
\text { cont } \\
\text { os }\end{array}$ & $\begin{array}{c}2-4,9 \\
\text { cont } \\
\text { os }\end{array}$ & $\begin{array}{c}5- \\
14,9 \\
\text { cont } \\
\text { os }\end{array}$ & $\begin{array}{l}>=15 \\
\text { contos }\end{array}$ & $\begin{array}{c}<2 \\
\text { conto } \\
\mathrm{s}\end{array}$ & $\begin{array}{c}2-4,9 \\
\text { cont } \\
\text { os }\end{array}$ & $\begin{array}{c}5- \\
14,9 \\
\text { cont } \\
\text { os }\end{array}$ & $\begin{array}{l}>=15 \\
\text { contos }\end{array}$ \\
\hline $\begin{array}{l}\text { Agric. de alimentos } \\
\text { Criação de gado } \\
\text { Erva mate }\end{array}$ & $\begin{array}{l}175 \\
160 \\
124\end{array}$ & $\begin{array}{l}69 \\
69 \\
46\end{array}$ & $\begin{array}{l}41 \\
41 \\
33\end{array}$ & $\begin{array}{c}12 \\
12 \\
7\end{array}$ & $\begin{array}{l}56 \\
51 \\
37\end{array}$ & $\begin{array}{l}41 \\
43 \\
36\end{array}$ & $\begin{array}{l}39 \\
39 \\
29\end{array}$ & $\begin{array}{l}3 \\
3 \\
2\end{array}$ \\
\hline $\begin{array}{l}\text { Total de } \\
\text { inventários }\end{array}$ & 192 & 73 & 42 & 13 & 67 & 46 & 42 & 3 \\
\hline
\end{tabular}

Fontes: vide a tabela 1.

Especialmente em São José dos Pinhais, a propensão a possuir ervais era relativamente alta em meio a patrimônios ínfimos (menores que dois contos de réis), tendo sido maior que entre os mais afortunados (15 contos de réis ou mais de patrimônio). Isso é muito significativo, mostrando um impacto imprevisto da proliferação de ervais retidos por pequenos proprietários. 0 destino dessa erva mate era certamente a espoliação mercantil, dado que possuir ervais não significava enriquecer, nem mesmo nesse momento do primeiro auge das exportações imperiais de mate. 
Para que se tenha ideia do significado desses ervais de pequenos proprietários, basta lembrar que quase com certeza seus proprietários sequer tinham renda anual suficiente para serem qualificados como votantes, nem mesmo se fossem homens que encabeçassem seus domicílios (sobre os não qualificados para votar em São José dos Pinhais em 1878, ver COSTA, 2008).

De outra parte, apesar de a situação verificada ter-se dado durante o primeiro auge oitocentista da exportação de mate paranaense (WESTPHALEN, 1998, p. 128, 519-520), desenrolava-se um processo institucional que tornava problemática a preservação desses patrimônios. Durante o século XIX, essas propriedades ervateiras enfrentavam uma onda de fragmentação, em virtude do aperto, motivado pela reconstrução estatal própria do período imperial, contra os mecanismos tradicionalmente usados para circundar a legislação de partilhas de bens (NAZZARI, 2001, p. 151-261). Isso pode ser flagrado nos próprios inventários. Comparando os processos abertos por ocasião das mortes dos dois membros de alguns casais, observa-se uma insuspeitada disciplina no cumprimento da lógica da meação. Isso é realizado para São José e Campo Largo e as informações constam do gráfico 1. Comparo os totais das fortunas inventariadas de mulheres e de seus maridos, diferenciando os casos em que mulheres faleceram antes dos homens daqueles em que o contrário ocorreu, ou seja, dos casos nos quais os maridos morreram primeiro. Os pontos representam os montantes das fortunas das mulheres no momento de suas mortes, expressando esses valores como percentagens do tamanho dos patrimônios dos maridos no instante dos falecimentos destes. Uma fortuna feminina de 100, por exemplo, significa que a mulher morreu possuindo fortuna idêntica à que seu marido tivera ou teria ao morrer (isto é, 100\%). Uma fortuna de 50 atribuída a uma mulher falecida dois anos depois de seu marido, para dar outro exemplo, significaria que ela, dois anos após a morte do sujeito, morreu possuindo fortuna equivalente à metade da dele. Pontos à esquerda do eixo vertical representam casos de mulheres falecidas antes de seus maridos. Pontos à direita do eixo vertical representam mulheres mortas após eles.

As informações não sugerem truques de reprodução. Quando maridos faleciam depois de suas mulheres (casos que aparecem alocados na parte do gráfico marcada por valores negativos no eixo horizontal), realmente tendiam a ter fortunas equivalentes à metade das que as senhoras haviam tido. Quando eram as mulheres que faleciam depois dos homens, eram elas que, efetivamente, mostravam ter tido patrimônios equivalentes à metade, ou até menos que isso, do de seus falecidos consortes. 
Isso faz ter alguma segurança de que ninguém estava conseguindo evitar o esfacelamento de fortunas por ocasião das partilhas. As heranças não só estavam diminuindo (o que se mede no gráfico são meações, e não legítimas, mas pode-se dar continuidade ao raciocínio), como estavam se tornando incongruentes e pouco viáveis enquanto negócios ou patrimônios que pudessem ser simplesmente continuados pela geração subsequente. Alguns impactos disso também podem ser entrevistos. Não eram muito comuns processos de avanço familiar entre as mortes de cada cônjuge, tendo sido raro que o segundo cônjuge a morrer fosse mais abastado que o primeiro. Também não se notam muitos processos de recuperação após o evidente baque consecutivo ao falecimento do primeiro cônjuge. A "pancada" da partilha igualitária era meio definitiva.

\section{Gráfico 1}

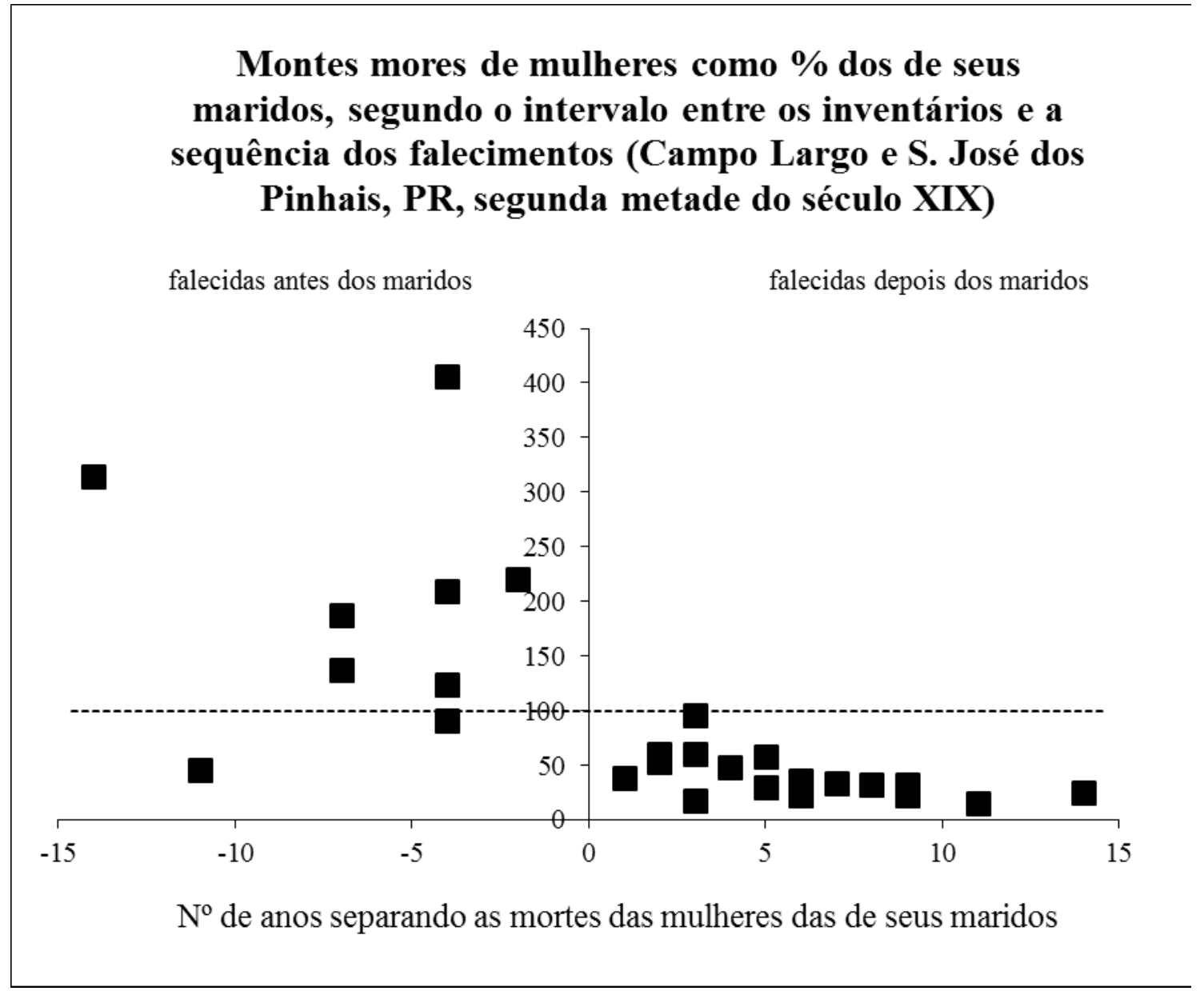

Fontes: ver tabela 1. 
Os peculiares proprietários do mate paranaense, fossem eles proprietários mais ou menos abastados, passavam não apenas por espoliação mercantil, mas também pelos efeitos da consolidação estatal sobre as estratégias de reprodução familiar. A aitividade ervateira, no entanto, continuava avançando, caminhando para novo pico de exportações no final dos anos 1880.

\section{Considerações finais}

As informações obtidas são congruentes com uma imagem segundo a qual a atividade ervateira se articulava ao modelo conhecido de produtores rurais submetidos a formas duras de domínio por parte do capital mercantil. A oligarquia ervateira, nesse sentido, mostra-se mais como oligarquia mercantil que como grupo industrial, ou coisa que o valha. Tratava-se praticamente de extrair excedentes de produtores de alimentos dando-se a tais excedentes a forma de erva coletada. A simplicidade derivada se manifesta em um trecho incisivo de Louis Couty. Referia-se ao mate paranaense, "comprado a 5 ou 10 francos os 100 quilos aos caboclos do Paraná, que o cortaram e secaram, na maioria das vezes sem o conhecimento dos proprietários; é em seguida transportado, preparado e revendido a 12 francos a arroba, 100 francos os 100 quilos, no porto de Antonina" (COUTY, 1984, p. 95; um franco suíço equivalia a aproximadamente \$450).

Nativa a erva e simples seu processamento, carecia a atividade de efeitos em cadeia que pudessem caracterizá-la como alguma espécie de análogo do complexo cafeeiro paulista. Constatar tal simplicidade, no entanto, não impede que se leve em conta seu enorme impacto do ponto de vista da renda e da formação de elites, impacto esse muito maior que o efetivado no tocante à paisagem.

Algumas comparações podem ajudar a mensurar o tamanho da atividade, mas também o quanto ela era exercida com pouquíssimos recursos produtivos. Em 1840-1841, o valor do café exportado pelo Império foi mais de sessenta vezes maior que o da exportação de mate; mas em 1857-1858 essa relação caiu, com a exportação de café tendo sido vinte e uma vezes maior, em valor, que a da erva (SOARES, 1977, p. 28-29, 99). As diferenças são enormes, mas não se deve esquecer que a soma apenas dos números de habitantes de Vassouras e Valença, na província do Rio, equivalia a quase todo a população que vivia no Paraná em meados da década de 1850, assim como que nada menos que sete municípios da província do Rio de Janeiro tinham mais escravos 
que todos os municípios paranaenses somados, e entre os municípios fluminenses aludidos figuravam Macaé, Rio Bonito, Piraí e Saquarema, além dos casos mais óbvios de Vassouras, Valença e Campos (PEREIRA, 1996, p. 59; SALLES, 2008, p. 185). Assim, a exportação per capita no Paraná era muitíssimo maior que o imaginado a partir do confronto dos valores exportados do mate e do café. A questão reside na circunstância de tudo isso ter tido tão poucos efeitos em cadeia, para frente ou para trás. A peculiaridade paranaense configurava, portanto, mais uma manifestação da proverbial capacidade dos modos de dominação tradicionalmente estabelecidos no Brasil de produzir quantidades gigantescas de riqueza sem alterar substancialmente a precariedade circundante, inclusive a precariedade econômica.

\section{Referências}

CAMPOS, Nazareno José de. Terras comunais na Ilha de Santa Catarina. Florianópolis: Editora da UFSC/FCC Ed., 1991

COSTA, Gladisson Silva da. Nos quarteirões de São José: um estudo sobre poder e sociedade em São José dos Pinhais na segunda metade do século XIX (1852-1878). Trabalho de Conclusão de Curso (Graduação em História), Curso de História - Bacharelado com Licenciatura, Universidade Federal do Paraná, Curitiba, 2008

COUTY, Louis. O Brasil em 1884. Esboços sociológicos. Brasília: Senado Federal, 1984

FONTELLA, Leandro Goya. Sobre as ruínas dos Sete Povos: estrutura produtiva, escravidão e distintos modos de trabalho no Espaço Oriental Missioneiro (Vila de São Borja, Rio Grande de São Pedro, c. 1828 - c. 1860). Dissertação (Mestrado em História), Programa de Pós-Graduação em História, Universidade Federal do Rio Grande do Sul, Porto Alegre, 2013

FRANCO NETTO, Fernando. População, escravidão e família em Guarapuava no século XIX. Guarapuava: Unicentro, 2007

Inventários post mortem, 1852-1886, Cartório da $2^{\text {a }}$ Vara Cível de São José dos Pinhais

Inventários post mortem, 1872-1885, Vara Cível de Campo Largo

Inventários post mortem, 1874-1888, Fórum de Palmeira, Vara Cível de Palmeira

KLEIN, Herbert. A oferta de muares no Brasil central: o mercado de Sorocaba, 1825-1880. In:

Estudos Econômicos. v. 19, n. 2, 1989 
LIMA, Carlos Alberto Medeiros. Uma "Informação" sobre os negócios da erva-mate e o seu autor (1837). In: História Econômica \& História de Empresas. v. XIV, n. 1, 2011

LIMA, Carlos A. M. Hierarquia e vida social em duas vilas do Paraná no primeiro terço do século XIX. In: SANTOS; BARROS; FALCI (org.). Espacialidades. Vassouras: LESC, 2004

LOBO, Eulália M. L. Evolução dos preços e do padrão de vida na cidade do Rio de Janeiro, 18201930. In: Revista Brasileira de Economia. v. 25, n. 4, 1971

MACHADO, Brasil Pinheiro. Terceiro caderno: A formação da estrutura agrária tradicional dos Campos Gerais. In: Três cadernos de História, idéias e reflexões. Curitiba: Arte e Letra, 2002

MACHADO, WESTPHALEN, BALHANA. Campos Gerais: Estruturas Agrárias. Curitiba: Editora da UFPR, 1968

MATTOS, Hebe. Das cores do silêncio. Rio de Janeiro: Arquivo Nacional, 1995

MENDES, Adilson Miranda. Origem e composição das fortunas na sociedade tradicional paranaense. Palmas - 1859-1903. Dissertação (Mestrado em História), Programa de PósGraduação em História, Universidade Federal do Paraná, Curitiba, 1989

MOTTA, Márcia Maria Menendes. Nas fronteiras do poder. Rio de Janeiro: Vício de Leitura; Arquivo Público do Estado do Rio de Janeiro, 1998

MUNIZ, Célia Maria Loureiro. A formação da fazenda de café em Valença: um estudo de processos jurídicos contra pequenos proprietários. In: SILVA, Francisco Carlos Teixeira da; MATTOS, Hebe; FRAGOSO, João (org.). Escritos sobre História e Educação. Homenagem à Maria Yedda Leite Linhares. Rio de Janeiro: Mauad/FAPERJ, 2001

MYSKIW, Antonio Marcos. A fronteira como destino de viagem: a Colônia Militar de Foz do Iguaçu (1888/1907). Tese (Doutorado em História), Programa de Pós-Graduação em História, Universidade Federal Fluminense, Niterói, 2009

NAZZARI, Muriel. O desaparecimento do dote. Mulheres, famílias e mudança social em São Paulo, Brasil, 1600-1900. São Paulo: Companhia das Letras, 2001

PEREIRA, Magnus R. de M. Semeando iras rumo ao progresso. Curitiba: Ed. da UFPR, 1996

PETRONE, Maria Thereza Schorer. O Barão de Iguape. São Paulo: Nacional; Brasília: INL, 1976

SALLES, Ricardo. E o Vale era o escravo. Vassouras, século XIX. Senhores e escravos no coração do Império. Rio de Janeiro: Civilização Brasileira, 2008

SMITH, Roberto. Propriedade da terra \& transição. São Paulo: Brasiliense; Brasília: CNPq, 1990 
SOARES, Sebastião Ferreira. Notas estatísticas sobre a produção agrícola e carestia dos gêneros alimentícios no Império do Brasil. Rio de Janeiro: IPEA/INPES, 1977 (ed. facsimilada da primeira, de 1860)

WACHOWICZ, Ruy Christovam. História do Paraná. 4ạ ed., Curitiba: Vicentina, 1977

WeSTPHAlEN, Cecília Maria. Porto de Paranaguá, um sedutor. Curitiba: Secretaria de Estado da Cultura, 1998

ZARTH, Paulo A. História Agrária do Planalto Gaúcho - 1850-1920. ljuí: Ed. da Unijuí, 1997 